\title{
Artificial hydration and alimentation at the end of life: a reply to Craig
}

\author{
Michael Ashby and Brian Stoffell Royal Adelaide Hospital and Mary Potter Hospice, and Flinders Medical \\ Centre respectively, Australia
}

\begin{abstract}
Dr Gillian Craig (1) has argued that palliative medicine services have tended to adopt a policy of sedation without hydration, which under certain circumstances may be medically inappropriate, causative of death and distressing to family and friends. We welcome this opportunity to defend, with an important modification, the approach we proposed without substantive background argument in our original article (2). We maintain that slowing and eventual cessation of oral intake is a normal part of a natural dying process, that artificial hydration and alimentation $(A H A)$ are not justified unless thirst or hunger are present and cannot be relieved by other means, but food and fluids for (natural) oral consumption should never be 'withdrawn'. The intention of this practice is not to alter the timing of an inevitable death, and sedation is not used, as has been alleged, to mask the effects of dehydration or starvation. The artificial provision of hydration and alimentation is now widely accepted as medical treatment. We believe that arguments that it is not have led to confusion as to whether or not non-provision or withdrawal of $A H A$ constitutes a cause of death in law. Arguments that it is such a cause appear to be tenuously based on an extraordinary/ordinary categorisation of treatments by Kelly (3) which has subsequently been interpreted as prescriptive in a way quite inconsistent with the Catholic moral theological tradition from which the distinction is derived. The focus of ethical discourse on decisions at the end of life should be shifted to an analysis of care, needs, proportionality of medical interventions, and processes of communication.
\end{abstract}

\section{Introduction}

Dr Gillian Craig (1) has raised what she sees as serious concerns about the ethical and legal aspects of the practice of palliative medicine, with particular regard to the non-provision of artificial hydration and alimentation (AHA). We will argue that the ethical reasoning which we have developed to describe our

\section{Key words}

Nutrition; hydration; death; dying; palliative care. practice of palliative care can accommodate $\mathrm{Dr}$ Craig's concerns (2). The sensitivities and consultative process of negotiation which she articulates are well heard, and we believe are already embodied in contemporary palliative care practice.

There is a broad consensus on aims and ethics of palliative care, and an internationally agreed WHO definition (4), although some diversity of clinical practice and ethical argument has emerged, particularly with regard to the relationship between palliative care and euthanasia $(5,6)$. This article is written from the perspective of an inpatient hospice unit which functions as the acute/crisis intervention facility for a comprehensive palliative-care network (hospital, hospice, home). There are no set policies about who may be admitted, and there is no arbitrary requirement for any therapeutic intervention to be stopped prior to admission. Many patients, particularly those who are young, or have haematological malignancies or AIDS, are in real need of hospice care for symptom control, respite or terminal care. However, they are not yet ready to stop having chemotherapy, blood transfusions, antibiotics or other so-called 'active' treatments with palliative intent, and AHA would certainly come under this category in our institution. A gradual process of negotiation will allow the cessation or non-initiation of treatment as the person's condition deteriorates. We agree that abrupt revision of treatment goals, particularly without adequate consultation of patient, family and staff will lead to anger and disharmony which may have lasting adverse consequences. Consequently communication with these persons is required, but it does not mean that the patient is treated in order to comfort the relatives. The issues raised by Dr Craig are discussed under two main headings: clinical, and ethical/legal.

\section{Clinical}

Dr Craig acknowledges the high public esteem for hospice and palliative care but goes on to state that 'some doctors have reservations'. The grounds for these are that there is a danger of patients being labelled as 'terminal' by the therapeutically inactive 
(palliative care) doctor. They may then be denied life-saving medical treatment which would be administered in the same situation by a treatmentorientated physician, perhaps for a wholly or partially reversible condition which has been misdiagnosed. Wilkes acknowledges that this is a real but rare eventuality, which does not occur more than a few times in a professional lifetime of palliative care practice ( 7 ), and probably no more so than in any other domain of medical practice. Dr Craig cites two case histories where patients were assessed as dying, but were rehydrated and survived. These constitute poor evidence for mistaken or possibly neglectful assessment in palliative care, even if the patients had been seen by a palliative care service (which is not stated). Careful clinical assessment is a sine qua non for any medical endeavour, and certainly before entry into any therapeutic model or protocol, although it is, of course, not infallible. When used to judge the robustness of the ethics of palliative care, these cases might at best fall into the category of hard cases which can be mobilised to undermine any approach. It is not suggested that cholecystectomy be banned because occasionally it is performed inappropriately. Many policies and probably most procedures or interventions in the medical context are dangerous if employed 'without due care and thought'. In our service patients from the main teaching hospital which we serve are accompanied by their notes and we insist on fuller clinical information than some referring doctors think is really necessary for palliative care.

\section{Three phases}

Dr Craig quotes from an article in which we described an approach based on three phases of a life-threatening incurable illness: curative, palliative and terminal, with different aims and levels of treatment-related morbidity being acceptable in each phase (2). A similar approach has been described for patients with cancer, for the purpose of making not for resuscitation orders (8). We stated that in the terminal phase 'no form of artificial hydration or alimentation is undertaken, all measures not required for comfort are withdrawn, and no treatment-related toxicity is acceptable' (8).

The framework we proposed was not intended to be a rigid and arbitrary 'policy', and we would not make a virtue of death without artificial hydration (in particular), as in some situations it might even be necessary for comfort right up until the time of death. We agreed that our model is ambiguous as presently worded, and should be amended by the addition of the following: ' $\ldots$ unless the effects of this are less than the benefits achieved by the treatment. For example, artificial hydration may be required in the terminal phase to satisfy thirst or other symptoms attributable to lack of fluid intake.'
Thus we give 'comfort measures' priority, 芦 including or excluding AHA as may be the case. It is further stated by Dr Craig that in the last few days of life the lack of food and drink will not contribute to $\stackrel{5}{\rightarrow}$ death and artificial hydration would not be appropriate, which is our point entirely.

\section{Important review}

It is also not usual 'policy' in hospices to sedate patients in order to mask any proposed unpleasant effects of dehydration. Rather sedation is administered when it is needed to alleviate suffering caused by acute organic brain syndromes (particularly where the underlying cause cannot be identified or reversed) and emotional distress for which other non-medical interventions have failed. It is possibly true that sedation may hasten the actual time at which relatively imminent death will occur. But it is not deemed necessary to hydrate sedated patients during the dying process when they are unable to maintain oral intake, as it makes no sense to attempt to treat a transiently reversible component of their overall dying process. Fainsinger and Bruera (9) have undertaken an important review of the clinical arguments for and against rehydration, and it is clear that there is more to learn about the physiology and clinical practice in this area of care. Dehydration can be a contributory cause of an organic brain syndrome, but these are usually multifactorial and in our experience rehydration alone rarely improves cognitive function in dying patients. It is also stated that staff in hospices would be more familiar with drips if they used them more often, and that it is this lack of practice which prejudices them against their use. In our hospice all staff are acute-care trained, and are therefore able to deliver whatever level of medical technology is required in the circumstances to maintain comfort (for example, spinal analgesia, venting gastrostomy, central venous lines, etc). They are always eager to learn new techniques which might benefit their patients. Subcutaneous fluid infusion (hypodermoclysis) has gained considerable acceptance as a N means of providing fluids in palliative care (10). This hopefully obviates any need for the practice, 尺 described by Wilkes, of infusing tap water into the rectum, especially if this practice is instituted to appease relatives (7).

In our view Dr Craig's real concerns are ethical and legal rather than clinical, and are based on a belief that medicine has a duty always to prevent death. This preoccupation with 'buying time' $\mathbb{D}$ suggests a belief that doctors are responsible for $\frac{\rho}{\mathbb{D}}$ death unless they do all possible to sustain life in all $\cong$ circumstances, a situation that Callahan calls 'technological brinkmanship': 'doctors still do not, 8 as a rule, talk comfortably and directly with patients? about death. ... A worry about malpractice, a zest for $\overline{0}$. technology, a deep-seated moral belief in the need to $\rightleftharpoons$ 
prolong life, and the pressure of families and others still often lead to overtreatment and an excessive reliance on technology' (11).

Such an approach may have unfortunate consequences for medical practice, and is in part responsible for the difficulties which many doctors experience with appropriate treatment abatement for dying people. If the care of dying people is to improve in all its settings, we need to try and address the issue of non-provision of AHA as a cause of death, which was raised by Dr Craig as there appears to be considerable confusion both within the medical and nursing professions, and also for many members of the public.

\section{Ethical and legal}

There is now a broad consensus that AHA should be regarded as medical treatment (12), and Beauchamp and Childress refer unequivocally to medically administered nutrition and hydration $(\mathrm{MN} \& \mathrm{H})$ (13). The decision whether or not to use AHA should be based on the balance of benefit and harm to the patient (therapeutic ratio). If AHA can be shown to have no medical benefit for the person, and potentially to cause harm and discomfort, there is a moral duty not to initiate or continue it.

On the other hand the 'natural' provision of food and water for oral intake is both a basic human need and a right, and no civilised person or health care institution could possibly argue for its non-provision or so-called withdrawal. It has been defined as follows: 'the provision of food and drink, to be taken voluntarily by mouth, to satisfy hunger or thirst ... [This] may include physical assistance (if requested by the patient) from another person, but does not include the administration of fluids or nourishment via nasogastric tubing or an intravenous line' (14).

The distinction between natural and artificial provision is made on the basis of what means are required to deliver the fluids and nutrients. All artificial techniques requiring intrusion on the person and medical and nursing skill for insertion and maintenance are medical treatments. In palliative care units food and drink, and assistance with eating and drinking are always available to satisfy a patient's thirst and hunger. But AHA is not routinely used when oral intake ceases, which is a normal part of the natural dying process. All treatments which are not required for comfort are stopped when a person is dying, and AHA, for example subcutaneous fluid infusion, is only used for symptomatic thirst or hunger which cannot be adequately treated by other means. Families and health care professionals are often uncomfortable with this practice. Although all therapeutic interventions should be for the benefit of the patient, the emotional needs and ethical views of the patient's family and care-givers must be acknowledged and considered. There must be recognition and fulfilment of the primary ethical duty to the patient, but the needs of those close to her or him must also be considered. The patient's decisions should determine how his or her medical treatment is to be conducted, but communication with family and friends, within the limits of respect for the patient's right to confidentiality, is almost always required. The way in which it is undertaken is a matter of skill, judgement and consultation. It should also be kept in mind that the degree of family involvement in individual patient decision-making can vary substantially between cultures.

There are two main polar approaches to decisionmaking at the end of life. Either the treatments or the persons to whom the treatments are applied are focused on. The two approaches are either one that would allow abatement of only certain treatments in all patients, or the other that would allow abatement of all treatments in certain patients. Somerville (15) argues against the ordinary/extraordinary distinction for deciding which treatments may morally be abated, on the grounds that it is not the treatments which tend to be so characterised but the patients to whom they are applied, and that this distinction allows subjective standards to be applied under the masquerade of objectivity. We would add the objection that it is not the duty of any moral,legal or medical commentator to decide a priori which treatments may or may not be chosen by a person or his/her substitute health care decision-maker or agent.

\section{Objective standards}

With respect to distinguishing patients, we would concur with Ramsey (16), Dyck (17), Grisez and Boyle (18) that a distinction is possible between those persons who are dying and those who are not (although we would hold some different views about treatment abatement for non-dying persons). A hard and fast objective clinical distinction as to when the dying process commences is not always possible, but the recognition of the existence of a natural dying process is central to the ethics and practice of palliative care (5). The objective standards consist of clinical evidence (disease progression, vital organ failure) and overt or covert psychological evidence (from both the person who is dying and family members: anticipatory grief, emotional withdrawal, future planning which acknowledges the impending death - for example, funeral planning in the context of terminal illness). Caution should be exercised in appearing to label people as 'dying', because of the attendant dangers of depersonalisation. There is no suggestion that people who are dying have diminished rights, or that their dying days are of less value than their nondying ones: it may be said that most people want to live until they die. Rather, their dying process should be acknowledged by all; their vulnerability increases our obligation to give care and respect, but does 
not lead us to give, and in fact, requires that we do not give, treatment which confers no benefit upon them.

Hydration and alimentation, including by artificial means, have become located in the category of so-called ordinary measures. Kelly (3) was the first to use the extraordinary/ordinary distinction to characterise specific treatments as either one or the other. In the orthodox interpretation of the Catholic moral tradition from which the concept is derived, as reviewed by Cronin (19) and described by McCormack (20), it is understood that it is up to individuals to decide, on the basis of proportionality, what constitutes ordinary and extraordinary treatment in their particular situation (Hepburn personal communication). A competent person determines what is ordinary or extraordinary for $\mathrm{him} / \mathrm{herself}$ in the particular situation when he or she gives informed consent or informed refusal, respectively, of the medical treatment in question. If that person is no longer able to take oral nutrition and fluid, and does not wish to have these provided artificially then there the matter rests, regardless of what others have to say about the 'ordinariness' of the treatment. For an incompetent person the situation is more problematical, and there are those who would argue, as Craig appears to, that AHA cannot be abated morally or legally by anyone on behalf of an incompetent patient, particularly if the incompetence is the result of medically induced sedation. In other words she appears to propose that the provision of alimentation and hydration is a truly ordinary measure, with the means of delivery being irrelevant to the moral duty to provide them, even when a person is dying. For those who conceptualise the issues in this way, there is a clear moral and legal 'bottom-line' for the treatment that may be withheld, namely only that of which provision is medically impossible or which would cause undue distress, in other words, only in the most extreme circumstances may treatment be withheld.

\section{'Assisted feeding'}

Weir (21) cites one of the most prolific and visible proponents of this position in the United States, Robert Barry OP. Barry relies on the amicus curiae brief of the New Jersey Catholic Conference in the Nancy Jobes case (22) and policy statements of the Committee for Pro-Life Activities of the National Conference of Bishops as evidence for his position as the correct interpretation of the tradition. Food and fluids, including AHA, should be given to all patients unless it is medically impossible to provide them. The term 'assisted feeding' is adopted to describe all provision of nutrition and hydration, and this is characterised as different from other medical treatments on the grounds that death inevitably results from non-provision; less skilled expertise is required to carry it out (tubes become passive conduits); and it is 'natural'. Assisted feeding is deemed to be always morally required, and moreover it is argued that this provides an acceptable objective $\Rightarrow$. moral standard which can stand firm against othere more subjective morally unacceptable standards ando tests that might be used in treatment abatement. In $\underline{\overline{0}}$ short, this stance is seen as a necessary safeguard $\frac{\bar{s}}{\bar{s}}$ against the so-called slippery slope to morally unacceptable withholding of treatment, with thes wider attendant societal effects which might ensuefrom AHA abatement.

A litany of suffering is listed as a consequence of $\overrightarrow{\vec{\omega}}$ starvation and dehydration, with no mention of the 9 effects of the underlying condition. The palliative care experience has simply not been like this, and there is no basis for believing that patients receiving palliative $-\overrightarrow{-}$ care are dying whilst suffering from symptoms of starvation and dehydration (13), which would be lessened or abolished by the routine provision ofo AHA. We agree that continual review of symptom-control profiles of patients in palliative care services isc necessary - with changes in treatment where necessary, including the provision of AHA (10).

For a potentially reversible condition, and for $\vec{\theta}$ people with incurable conditions who are not yet. ${ }^{\circ}$ dying, artificial hydration and alimentation (AHA) is a medical treatment which must be offered. For incompetent persons with irreversible brain damage, the decision to cease AHA should depend on anyo available evidence of prior wishes of the person, and $\mathbb{Q}$ where such evidence is not available or is unclear, on $\overrightarrow{\vec{O}}$ their best interests, and not on a preconceived 3 position on the obligatoriness of AHA. Nearly all the? legal deliberations on the provision or withholding of? AHA have been for people in this category. As Dr Craig states, the issue of AHA abatement for dying $\Phi$ persons has not been specifically tested in the courts of the United Kingdom, and the most relevant recent legal deliberations are those in Airedale NHSO Trust $\mathrm{v}$ Bland (12). Tony Bland was not dying, but was irrefutably in a persistent vegetative state (PVS)윽 from which no prospect of recovery was deemed possible, by all but one dissenting piece of medical evidence (23). The judgment of the House of Lords ज permitted the discontinuation of AHA, which was acknowledged to be his life support, on the grounds that since it was not in his best interests (because he ${ }^{\mathrm{W}}$ no longer had an interest in being alive owing to an absence of higher cognitive function) there was noo duty to continue this treatment. Bland cannot be directly extrapolated to the case of dying people, as they may well be sensate until the moment of death, $\frac{0}{0}$ and often will have both an interest in being alive and the means to express that interest. Nonetheless, $\frac{?}{\mathbb{D}}$ the deliberative process in the Bland case has been 2 helpful to all who study decision-making at the ende of life, although the court's emphasis on the act- 8 omission distinction, with respect, may have been? excessive (24); and if the patient's best interests arê⿳亠 identified as the main concern, the problem still? 
remains of who determines them - it can be argued that there was an over-reliance on doctors by the court in the Bland case.

The crucial question is whether the dying person's interests are served by the provision of AHA, and this must surely be a decision based on what these measures can contribute to the person's comfort and quality of life. There are three groups of considerations to take into account in determining this. First, if these measures are requested, or are identified as necessary for comfort by attending staff or family members and may be effective in achieving the stated aims, then they should not be refused. It seems that there is no case law on the issue of AHA abatement for dying persons because no court has been asked specifically to consider it. This seems to indicate that in practice it has not been seen to be an issue which requires legal judgment. There is no established or accepted duty that in all cases hydration and alimentation must be maintained by whatever medical means available until death. Moreover, if AHA was not required for Bland who, unlike the dying person was not actually and actively dying of a progressive fatal condition at the time of the judgment, there is even less basis for saying that it is required for all dying persons.

\section{Unpleasant side-effects}

Second, all forms of AHA carry associated unpleasant side-effects and possibly may induce premature death. The introduction of a nasogastric tube is unpleasant and its continued presence is usually a source of discomfort and irritation, and regurgitation and inhalational (overspill) pneumonia are common when patients are weak and debilitated. Venous lines can cause infective complications, and neck lines are uncomfortable and potentially hazardous to insert. Tubes and lines also become blocked or dislodged, and their replacement can be unpleasant and distressing, particularly for conscious patients with cognitive impairment. For incompetent patients in whom there is a prospect of recovery all of these problems will usually be regarded as acceptable, but the same trade-offs could not possibly apply to people who are dying.

Third, the shortening or lengthening of life can be an issue associated with the provision or nonprovision of AHA. Whilst such provision or nonprovision of AHA may influence the timing of an anticipated death, it is not usually possible to predict in which way, ie, whether death would occur sooner or later than it would have done otherwise. We argue, that just as in the consideration of the issue of pain control for dying persons, the influence on timing of death should be a secondary consideration to the comfort and dignity of the dying person.

A number of legal reports and judgments have addressed treatment abatement and palliative care, and analysed the issues this raises of duties to provide care and treatment, and regarding causation of death. The non-initiation or continuation of AHA will not constitute a cause of death in the eyes of the law, if there is no duty to provide it. In such cases causation is an irrelevant consideration, because if there is no duty there can be no breach of duty which might be a cause of death of the person. From a legal point of view, in such cases the cause of death is the underlying condition which has led to the absence of oral intake, and the use of sedation for the palliation of another symptom, as an essential component of care in an otherwise natural dying process, does not alter this. There is no place for emotive language about killing patients in this context.

With respect to determining when a medical practitioner has a duty to provide care, in 1982 the Canadian Law Reform Commission recommended that: 'the law should recognise that the prolonging of life is not an absolute value in itself and that therefore a physician does not act illegally when he fails to take measures to achieve this end, if these measures are useless or contrary to the patient's wishes or interests'; and: 'the law should recognise that the incapacity of a person to express his wishes is not a sufficient reason to oblige a physician to administer useless treatment for the purpose of prolonging life' and 'the law should recognise that in the case of an unconscious or incompetent patient, a physiciar incurs no criminal responsibility by terminating treatment which has become useless' (25).

In other words, in each of the three sets of circumstances represented by these statements of the commission, there is no legal duty on the physician to initiate or to continue to provide useless treatment, or that which is refused by a competent person.

A court in New Zealand authorised withdrawal of ventilation from a man rendered incompetent and completely paralysed by an extreme form of the Guillain-Barré syndrome. In this case, Justice Thomas throws light on what might be termed 'useless' with regard to medical care: 'Medical science and technology has advanced for a fundamental purpose: the purpose of benefiting the life and health of those who turn to medicine to be healed. It surely was never intended that it be used to prolong biological life in patients bereft of the prospect of returning to an even limited exercise of human life. Nothing in the inherent purpose of these scientific advances can require doctors to treat the dying as if they were curable. Natural death has not lost its meaning or significance. It may be deferred, but it need not be postponed indefinitely' (26).

Gillon suggests that, where the negotiation and communication process has broken down, a mediation process should exist for situations involving differences of opinion about whether a person with a terminal illness should receive AHA (27). This may be useful in very difficult situations, 
where referral to an institutional ethics committee or bioethical consultant may also help. It is to be hoped that this need can usually be avoided by the sensitive and appropriate raising of the issues addressed in this paper. Due regard is, however, required for the cultural and ethnic dimensions involved. Families who feel that they are neglecting their role and duty in the provision of nourishment will not appreciate having a discussion about the ethical or legal issues raised in relation to treatment abatement. They are, however, much more likely to agree to a care plan which is gently worked out with them, where all parties agree on their common values concerning the comfort, value and integrity of the person who is dying, and the absence of anyone's responsibility for that dying.

In conclusion, we believe that the approach which we have described here is the dominant one in modern palliative care practice, and is accepted in the mainstream of contemporary ethical discourse. We agree with Beauchamp and Childress who see: '... no reason to believe that medically administered nutrition and hydration is always an essential part of palliative care or that it necessarily constitutes, on balance, a beneficial medical treatment' (13).

\section{Acknowledgements}

Michael Ashby was supported by the Special Purposes Fund of the Royal Adelaide Hospital. Thanks to the director (Professor Margaret Somerville) and staff of the Centre for Medicine, Ethics and Law, McGill University, Montreal, Quebec, Canada and to Dr Liz Hepburn IBVM, Director of the Provincial Bioethics Centre for the Dioceses of Queensland, for their assistance in writing this paper.

Michael Ashby, MBBS, MRCP (UK), FRCR, FRACP, MRACMA, is Professor of Palliative Care, Monash University, based at Monash Medical Centre, Clayton, Victoria 3168. Brian Stoffell, $B A, P h D$, is Director, Medical Ethics Unit, Flinders Medical Centre and Flinders University of South Australia.

\section{References}

(1) Craig G M. On withholding nutrition and hydration in the terminally ill: has palliative medicine gone too far? Fournal of medical ethics $1994 ; 20$ : 139-143.

(2) Ashby M A, Stoffell B. Therapeutic ratio and defined phases: proposal of ethical framework for palliative care. British medical journal 1991; 302: 1322-1324.

(3) Kelly G. Medico-moral problems. St Louis: The Catholic Hospital Association of US and Canada, 1954: 6-15.

(4) Cancer pain relief and palliative care. Technical Report Series 804. Geneva: World Health Organisation, 1990.
(5) Ashby M A, Brooksbank M A, Stoffell B. Natural death and the ethics of palliative care. [In $\overline{\bar{C}}$.
preparation].

(6) Hunt R. Palliative care - the rhetoric-reality gap. In: Kuhse $\mathrm{H}$, ed. Willing to listen, wanting to die. $\stackrel{\text { ? }}{9}$ Melbourne: Penguin Australia, 1994.

(7) Wilkes E. On withholding nutrition and hydration in the terminally ill: has palliative medicine gone too far? $\frac{\bar{s}}{7}$ A commentary. Fournal of medical ethics 1994;20:市

(8) Haines I E, Zalcberg J, Buchanan J D. Not-forresuscitation orders in cancer patients - principles of $\overrightarrow{0}$ decision making. Medical journal of Australia 1990; 153: 225-229.

(9) Fainsinger R, Bruera E. The management of dehydration in terminally ill patients. Fournal of palliative care $1994 ; 10: 55-59$.

(10) Bruera E, Legris $M$ A, Kuehn N, Miller M J. Hypodermoclysis for the administration of fluids and narcotic analgesics in patients with advanced cancer. $\vec{\omega}$ fournal of pain and symptom management 1990; $5:$ 윽
$218-220$.

(11) Callahan D. The troubled dream of life: living with $\vec{c}$ mortality. New York: Simon Shuster, 1993.

(12) Airedale NHS Trust $v$ Bland. [1993] 1 ALL ERत्ठ 821-896.

(13) Beauchamp T L, Childress J F. Principles of biomedical $\overrightarrow{0}$ ethics. New York: Oxford University Press, 1994.

(14) Ashby M. Law reform on death - over but not out. Australian health law bulletin 1994; 2: 81-85.

(15) Somerville M. Advice to the Minister for Health of South Australia on the Consent to Medical Treatment and Palliative Care Bill, Dec 1992 [unpublished].

(16) Ramsey P. Prolonged dying: not medically indicated. Hastings Center report 1976; 6: 14-17.

(17) Dyck A. Ethical aspects of care for the dying incompetent. Fournal of the American Geriatric Society? 1984; 32: 661-664.

(18) Grisez G, Boyle J M. Life and death with liberty and justice. Notre Dame, Indiana: University of Notre Dame Press, 1979.

(19) Cronin D A. Conserving human life. Doctoral dissertation [1958] republished in Cronin D A. Conserving human life. Boston, Ma: The Pope John 을 Center, 1989.

(20) McCormack R. The quality of life, the sanctity of life. 을 Hastings Center report 1978; 1: 30-36.

(21) Weir R F. Abating treatment with critically ill patients. 을. New York: Oxford, 1989.

(22) In re Jobes, 108 NJ. 394, 529 A.2d 434 (1987).

(23) Andrews K. Patients in the persistent vegetative state: 응 problems in their long term management. British medical journal 1993; 306: 1600-1602.

(24) Collins D. Prescribing limits to life-prolonging treatment. AIC Medical Conference. Auckland 1994 Apr 19-20.

(25) Law Reform Commission of Canada. Protection of life: euthanasia, aiding suicide and cessation of treatment. Working paper 28. Ottawa, 1982.

(26) Auckland AHA v A-G. [1993] 1 NZLR 235.

(27) Gillon R. Palliative care ethics: non-provision of artificial nutrition and hydration to terminally ill sedated patients. Fournal of medical ethics 1994;20:ত 131-132. 